Instructions for authors, subscriptions and further details:

\title{
Learning with Adults: A Critical Pedagogical Introduction
}

Tatiana Iñiguez Berrozpe ${ }^{1}$

1) University of Zaragoza, Spain

Date of publication: October 25th, 2017

Edition period: October 2017 - February 2018

To cite this article: Iñiguez Berrozpe, T. (2017). Learning with Adults: A Critical Pedagogical Introduction [Review of the Book]. International Journal of Sociology of Education, 6(3), 374-375. doi: 10.17583/rise.2017.2996

To link this article: http://dx.doi.org/10.17583/rise.2017.2996

\section{PLEASE SCROLL DOWN FOR ARTICLE}

The terms and conditions of use are related to the Open Journal System and to Creative Commons Attribution License (CC-BY) 


\section{Reviews}

English, L.M. \& Mayo, P. (2012). Learning with Adults: A Critical Pedagogical Introduction. Rotherdam: Sense Publishers

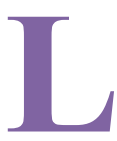

eona English, profesora de educación para adultos, y Peter Mayo, académico universitario especializado en educación a lo largo de la vida, presentan una obra que, dentro de la pedagogía crítica, y frente a la concepción instrumental del capital humano de las políticas neoliberales y la globalización, aboga por una concepción transformadora de la educación para adultos.

En este sentido, la premisa de partida de los autores es la defensa de la educación a lo largo de la vida como una herramienta de emancipación, empoderamiento y transformación personal y social. Así, su trabajo se conforma cómo si de un "manifiesto por la educación de adultos" se tratase, desde una perspectiva freiriana. Sin ir más lejos, tal y como el subtítulo del libro destaca, la teoría del pedagogo brasileño impregna toda la obra de English y Mayo. Su pedagogía crítica, desde el desarrollo de la conciencia de libertad, la acción constructiva y el empoderamiento personal y comunitario, tiene en la educación de adultos la herramienta indispensable para la lucha contra la opresión y el logro de una sociedad basada en preceptos de democracia real, conectando así pedagogía y política. Por tanto, la intencionalidad de los autores es clara, tomando como referencia a Freire y Gramsci, plantear la educación de adultos o lifelong learning como una acción crítica que supere concepciones meramente pragmáticas o tecnocráticas, y se constituya en desafío pedagógico, político y económico.

El trabajo de Leona English y Peter Mayo se divide en cuatro secciones. La primera, Contextualising Adult Education, los autores se plantean cuál es y cuál debería ser el papel de la educación de adultos en la sociedad actual. Para ello, y como especificábamos anteriormente, emplean una mirada crítica sobre el posicionamiento neoliberal y globalizado acerca de la función de este aprendizaje. Frente a ello, defienden la acción del lifelong learning desde el punto de vista local, como herramienta de mejora de la ciudadanía. En la segunda sección, Contemporary Theoretical Perspectives on Adult Education, y como su nombre indica, los autores recogen diferentes 
aproximaciones teóricas sobre la educación de adultos, partiendo de la teoría marxista. Si bien, en los capítulos subsiguientes, teorías posmodernas como las feministas, las relativas al capital humano y la crítica a la teoría sistémica, tienen cabida para reflexionar sobre todas las implicaciones sociales de esta temática. La tercera sección, denominada Contexts of Practice in Adult Education, ejemplifica cómo la educación de adultos tiene lugar en distintos contextos, entendiéndola no sólo como aprendizaje a lo largo de la vida (lifelong learning), sino también a lo ancho (lifewide learning [concepto no citado en el libro, pero que recoge la esencia de la idea de los autores]), dadas las distintas formas en las que puede presentarse: educación formal, no formal e informal. Es también en este capítulo donde English y Mayo desarrollan su teoría más crítica al hablar de los lugares de trabajo como centros promotores de la formación para adultos donde, en muchas ocasiones, el neoliberalismo reduce a sus trabajadores a meros recursos. En contraposición a ello recogen otras experiencias, como las de los movimientos sociales, donde el cambio de esta concepción materialista de la educación para adultos hacia otra de tipo transformador está siendo más apreciable. La última parte, Concerns in the Practice of Adult Education, recoge las principales cuestiones clave sobre la educación de adultos en la actualidad, incluyendo temas como la multiculturalidad, la educación para la salud o la educación de adultos mayores.

La conclusión de English y Mayo es que la construcción de un "mundo mejor" pasa necesariamente por la educación de adultos como herramienta de transformación de la ciudadanía y, por ende, de las desigualdades sociales, desde una perspectiva emancipadora. Esta reflexión resulta esencial en un momento en el que la inversión pública en educación de adultos no sólo no se mantiene, sino que se va reduciendo en numerosos países europeos, entre los que se incluye España. En este sentido, cabe preguntarse si, precisamente, lo que buscan las instituciones es la descomposición de una masa crítica que las cuestione. Temas políticos aparte, en la sociedad del riesgo actual, tal y como los autores propugnan, la principal arma de empoderamiento es la educación a lo largo (y ancho) de la vida.

Tatiana Iñiguez Berrozpe, Universidad de Zaragoza tatianai@unizar.es 